\title{
Late Pleistocene hydroclimate reconstructions of 12 pluvial lakes in Western North America
}

\author{
ALEXANDREA JAY ARNOLD AND ARADHNA TRIPATI
}

\section{UCLA}

Presenting Author: ajarnold1@g.ucla.edu

During the Last Glacial Maximum (LGM, 20,000 years ago), greenhouse gas concentrations were reduced, large ice sheets were prevalent in North America, and cooler temperatures and wetter conditions prevailed, which allowed for the existence of hundreds of pluvial lakes in Western North America. However, the hydrologic mechanisms that drove the existence of lakes and their fluctuations throughout time, and overall fate of desiccation has been highly debated. In this study, we explore hydrological changes that occurred throughout the LGM into the deglaciation by synthesizing data from several collaborative studies that use carbonates from 12 closed-basin lakes that encompass a wide range of modern and past climates in Western North America $\left(24-42^{\circ} \mathrm{N}, 100-120^{\circ} \mathrm{W}\right)$. This work allows us to develop and refine lake hydrographs for each basin by applying radiocarbon dating on shoreline samples, allowing for comparison of lake level fluctuations through both time and space. We also apply carbonate clumped isotope thermometry to our samples to estimate past lake water temperatures and lake water $\mathrm{d} 18 \mathrm{O}$, and use these estimates in concert with a hydrologic isotopic mass balance model to constrain past annual precipitation and evaporation rates. We apply our quantitative estimates of evaporation and precipitation to test hypotheses on the evolution of moisture transport and sources and the magnitude of precipitation changes. In addition, we compare our estimates of precipitation, and temperature estimates to a transient climate model (TraCE-21ka), and quantitatively assess model performance over our entire time interval. 